\title{
ANALYTICAL AND NUMERICAL ANALYSIS OF S. MARTINO'S DEI GUALDESI CHURCH DAMAGED DURING THE 2016 CENTRAL ITALY SEISMIC SEQUENCE
}

\author{
Elvis Cescatti ${ }^{1}$, Michol Rampado ${ }^{1}$, Veronica Follador ${ }^{2}$, Francesca da Porto ${ }^{1}$, Claudio \\ Modena $^{3}$ \\ ${ }^{1}$ Depart. of Geosciences - University of Padova \\ Via G. Gradenigo, 6, 35131 Padova (IT) \\ elvis.cescatti@dicea.unipd.it; michol.rampado@dicea.unipd.it; francesca.daporto@unipd.it
}

${ }^{2}$ DICATAM - University of Brescia

Via Branze, 43, 25123, Brescia (IT)

v.follador@unibs.it

${ }^{3}$ ITC - CNR

Corso Stati Uniti, 4, 35127, Padova (IT)

claudio.modena@unipd.it

\begin{abstract}
The seismic response of churches is peculiar due to the building typology, the structural features and the used materials. During last decades a great work of research on damages occurred on such structures after seismic events was performed and some insight of this behavior have pointed out suggesting different intervention techniques. This lead to apply, during past years, some interventions on churches already damaged. In particular, the Umbria-Marche region, has stroked by three relevant earthquakes: Norcia 1979 (Mw 5.8), Colfiorito-Annifo 1997 (Mw 6.0), Norcia 2016 (Mw 6.5). The last events occurred on structures already damaged in past and strengthened by interventions that aim at improving their seismic behavior.

Starting from the conclusions of such extended survey campaign and analyzing the effect of interventions, the Church of S. Martino's dei Gualdesi in Castelsantangelo sul Nera (MC Italy) was modelled and studied with both linear and non-linear methods.

The paper presents the results of such analysis comparing also the observed damages and the effectiveness of some interventions preformed in past years on the church.
\end{abstract}

Keywords: Masonry Churches, Seismic Vulnerability, Numerical Analysis, Limit Analysis. 


\section{INTRODUCTION}

The study of structures damaged from earthquakes is the most interesting benchmark to evaluate the analytical and numerical tools available in the vulnerability analysis and commonly used to design retrofit or refurbishment interventions.

The study herein reported is a preliminary stage of a deeper project carried out on the San Martino's dei Gualdesi Church. The case-study selection derives from a wider observation on a dataset of about 900 churches stricken by the 2016 earthquake swarm [1] that recognize in Castelsantangelo sul Nera, an interesting opportunity to evaluate vulnerability and effect of interventions.

The paper presents a qualitative evaluation of interventions carried out in the municipality and reports the analysis carried out on San Martino. The presented analysis looks at the unreinforced church and aims at evaluating the seismic multiplier. Moreover, a non-linear static analysis has carried out to evaluate its reliability in predicting the damage pattern and to support the kinematic analysis.

\section{RESPONSE OF CHURCHES IN CASTELSANTANGELO SUL NERA}

The municipality of Castelsantangelo sul Nera, located in the Marche Region, was interested by numerous seismic events in past years and also by the 2016 Central Italy seismic swarm. This last caused severe damage to structures including the churches of the region [2].

In order to evaluate the vulnerability and the seismic response of such structures, a focus on the municipality cluster, composed by 19 cases, was carried out beginning form the enlarge database collected in the Centre of Italy [1]. All the churches in the cluster undergone a PGA between $0.52 \mathrm{~g}$ and $0.54 \mathrm{~g}$ evaluated by INGV shake-maps. Therefore, considering similar actions, the damage observed is mainly guided by the vulnerability of each structure.

The Damage Index $\left(i_{d}\right)$ has evaluated by the A-DC form $[3,4]$ and the Vulnerability Index (iv $)$ was first defined according to the II level form for the church survey [5]. The $i_{d}$ have shown an high heterogeneity, ranging from 0.33 to 0.85 (variation of 0.52 , average of 0.52 and standard deviation of 0.14 ) that could be attributed to the vulnerability of the constructions since the seismic actions were quite similar. The analysis of $i_{v}$ did not show significant variations varying between 0.36 and 0.57 (average of 0.48 and standard deviation of 0.06 ). This could lead to suggest a small representativeness of the $i_{v}$ value to describe the different vulnerabilities, suggested also by the fact that the variation of the damage index calculated by formulation available in literature [6] would be 0.09 , for the $i_{v}$ and PGA values ranges herein described.

To better highlight the raised differences, a specific evaluation on each case has performed, also considering the consolidation interventions carried out in past years with the aim of obtaining insight into their effect on the seismic response.

From the observation of all cases, some intervention highlighted always a positive behavior such as tie rods applied for both goals: prevent the out-of-plane mechanisms of the walls and counterbalance the loads of arches and vaults. This intervention pointed out some issues only in case of poor masonry quality with the disaggregation of wall [7]. Another very positive intervention is the introduction of a metallic hopping system on the bell-tower. Indeed, two churches two hundred meters close, very similar in geometry and dimensions, like S. Stefano and San Martino's dei Gualdesi pointed out two emblematic boundaries in behavior (Figure 1) between the total collapse and only a cracking of the bell-tower due to the presence, in the case of St. Martino, of hooping interventions on the belfry that avoid the collapse after the mechanism activation. On the other hand, some interventions show generally worsening effects such as some concrete slab reinforcement of roofs, where due to the increase of loads and stiffnesses, masonry collapse or severe damage occurred. The task of containing the overturning of the 
walls and distributing the vertical loads was entrusted to the ring beam. Sometimes, it was observed an overall achievement of the goal, whereas either in the case of reinforced concrete ring beam and in the steel beam sometimes some damage caused by this intervention were observed such as horizontal cracks at the height of the ring beam and the disintegration of the masonry below it. The causes can be associated with poor masonry quality as well as an ineffective or absent connection between the ring beam and the masonry.

The results obtained from this analysis have determined different responses in terms of local and global damages although the earthquake was the same. For these reasons, in order to understand which parameters have the greatest influence on the vulnerability, a seismic behavior analysis of a specific church, that may represent the cluster, has been implemented and herein presented.
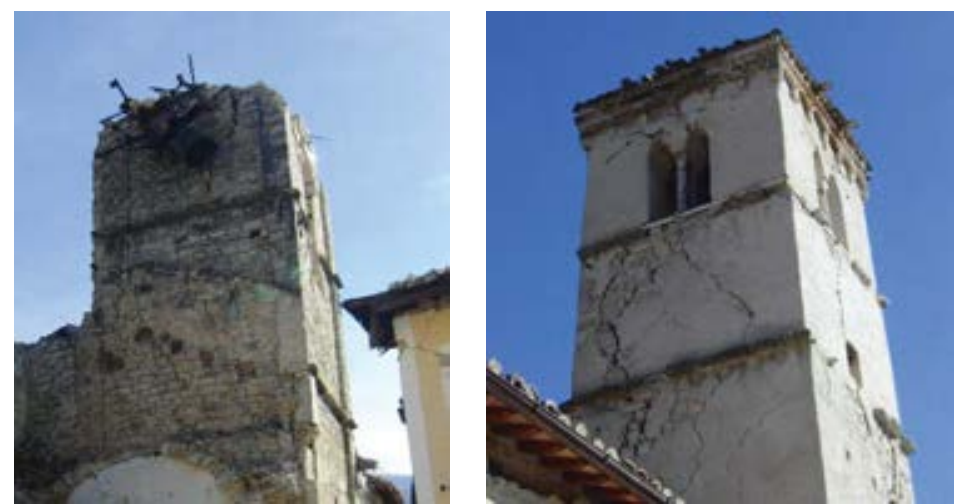

Figure 1: S. Stefano's tower (left) and San Martino's bell tower (right) after the $30^{\text {rd }}$ of October 2016

\section{SAN MARTINO'S DEI GUALDESI CHURCH}

San Martino's dei Gualdesi church, in Castelsantangelo sul Nera (MC), was built in the $14^{\text {th }}$ century. The structure is mostly made of local limestone (two leaves masonry 70-120 cm thick) and lime mortar. The structure is $30.60 \times 7.40 \mathrm{~m}$ in plan and $6.87 \mathrm{~m}$ height for the nave with an height of $17 \mathrm{~m}$ for the tower and it is of medium size compared to those present in the region [1]. The church consists of a single nave, marked by four pointed arches arranged transversely, covered by a timber gable roof. Externally, the church has the same internal regularity: the longitudinal south-west facade is characterized by two entrance portals and by further secondary openings. The transversal gabled facade, located to the north-west side, is composed by a simple window in the central area.

The structural data were entirely deduced from the information collected during the on-site surveys and through some documentary additions provided by the Superintendence for Cultural Heritage of Ancona. To date, it has not been possible to carry out diagnostic campaigns for the characterization of construction details or materials. For this reason, the materials' mechanical properties were obtained from a critical analysis of masonry arrangements by the study of the masonry quality index (IQM) [8] of some panels and masonry sections. These investigations with its typological and qualitative definition helped in identify two different masonry typologies according to the Italian National Standard [9], whose mechanical properties [10] are summarized in Table 1.

In this case, since the investigations are limited, the confidence factor calculated according the Italian guidelines for cultural heritage [11] is equal to 1.24 and the level of knowledge reached is KL1. 


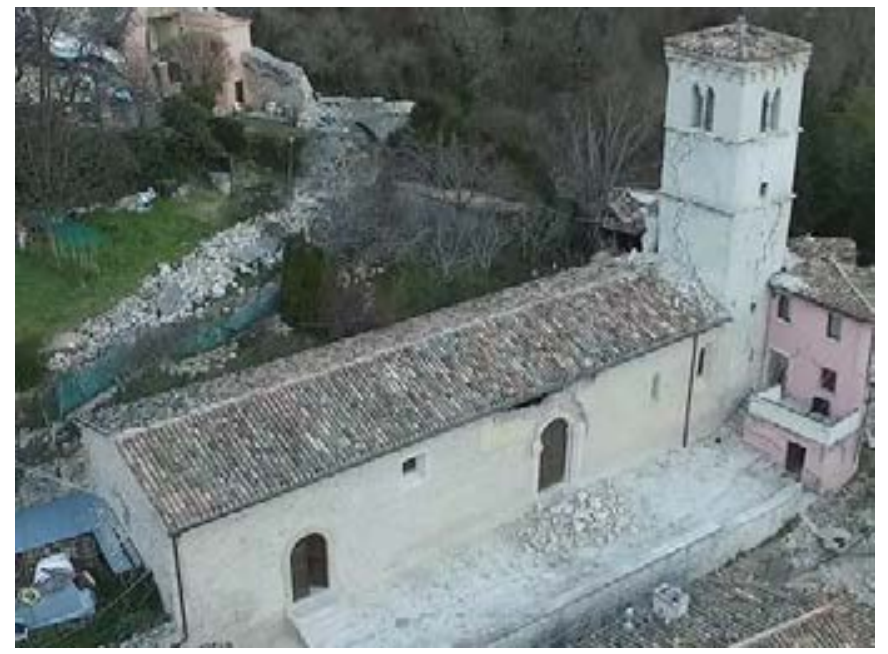

a)

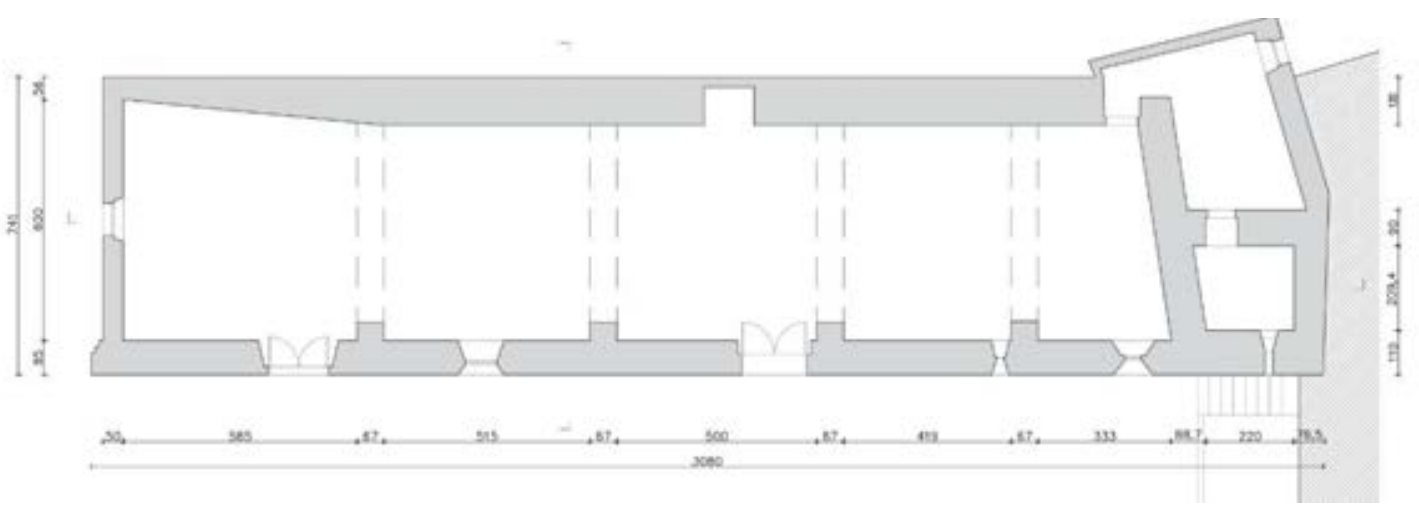

b)

Figure 2: Aerial view (a), and plan (b) of San Martino’s dei Gualdesi church.

\begin{tabular}{lccccc}
\hline MASONRY TYPOLOGIES & $\begin{array}{c}\boldsymbol{f}_{\boldsymbol{m}, \boldsymbol{d}} \\
\left(\mathbf{N} / \mathbf{m m}^{\mathbf{2}}\right)\end{array}$ & $\begin{array}{c}\boldsymbol{\tau}_{\mathbf{0 , d}} \\
\left(\mathbf{N} / \mathbf{m m}^{\mathbf{2}}\right)\end{array}$ & $\begin{array}{c}\mathbf{E} \\
\left(\mathbf{N} / \mathbf{m m}^{\mathbf{2}}\right)\end{array}$ & $\begin{array}{c}\mathbf{G} \\
\left(\boldsymbol{N} / \mathbf{m m}^{\mathbf{2}}\right)\end{array}$ & $\begin{array}{c}\mathbf{W} \\
\left(\boldsymbol{k N} / \boldsymbol{m}^{3}\right)\end{array}$ \\
\hline $\begin{array}{l}\text { Masonry: Roughly cut stone ma- } \\
\text { sonry with good texture - III }\end{array}$ & 2.6 & 0.056 & 1740 & 580 & 21 \\
\hline $\begin{array}{l}\text { Arches: Stone blocks squared ma- } \\
\text { sonry- V }\end{array}$ & 5.8 & 0.090 & 2850 & 950 & 22 \\
\hline
\end{tabular}

Table 1: Mechanical properties of the masonries used.

\subsection{Interventions related to the past seismic events}

The most significant earthquakes for the Castelsantangelo sul Nera area were the earthquakes of Norcia, $M_{w} 5.8$ in 1979, and the Umbria-Marche earthquake, $M_{w} 6.0$ in 1997. These seismic events had a strong impact with regard to both the identification of seismic damage and the implementation of series of interventions aimed at mitigating its effects (not always with real benefits). The church of San Martino's dei Gualdesi, entering into this context, was subjected to four intervention campaigns (in 1988, 1999, 2000 and in 2014). Some of the older interventions had been replaced in subsequent refurbishments. Therefore, a description of the present configuration of the church with the current interventions is presented below.

In general, two significant phases of intervention can be distinguished: one relating to the 2000 restorations, which mainly involved the bell tower, and a more recent restoration of 2014 regarding the structure of the nave.

In 2014 interventions, a systematic demolition of the top of the wall was carried out with subsequent reconstruction of it for a height of $30-50 \mathrm{~cm}$. In addition, a UPN 220 metal profile 
has been inserted and anchored with the underlying wall with a $\phi 16$ bar $85 \mathrm{~cm}$ long, every 50 $\mathrm{cm}$. The bars were inserted inside perforations (with a diameter of $24 \mathrm{~mm}$ ) and subsequently injected with lime mortar (blue line in Figure 3). A further intervention was the injection of a fluid hydraulic lime mortar on the walls. Four holes per square meter with a diameter of $22 \mathrm{~mm}$ were injected (red dot fill in Figure 3). A final and significant structural intervention performed on the nave concerns the execution of a series of steel bars reinforcement between the longitudinal walls of the nave and the internal arches. Twelve stainless steel bars with a diameter of $16 \mathrm{~mm}$ were inserted and injected with epoxy resin inside drillings of $24 \mathrm{~mm}$ of diameter (red strip hatch in Figure 3). Regarding the bell tower, in 2000, two orders of metal hooping beams have been inserted in elevation under the belfry and at the level of the mouldings (blue dashed line in Figure 3). Finally, about 20 perforations per wall were made on the tower's walls with subsequent insertion of steel bars presumably with a diameter of $20 \mathrm{~mm}$ (green dot mesh in Figure 3).

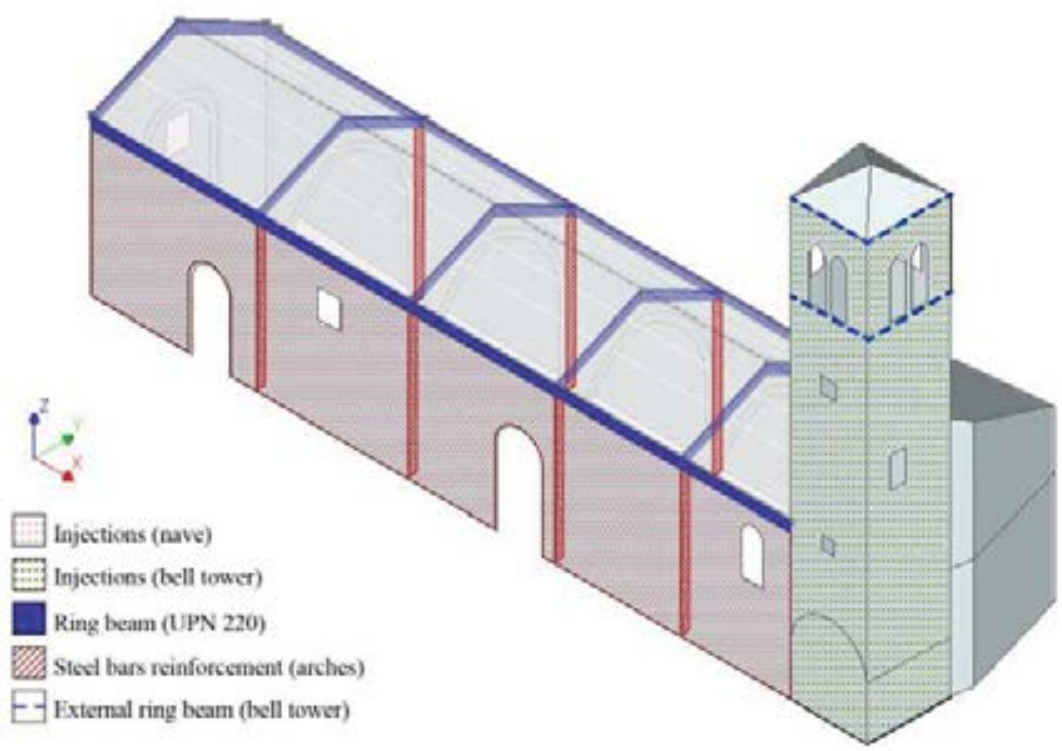

Figure 3: Representation of interventions implemented in 2014 and 2000 to the San Martino's dei Gualdesi church.

\subsection{Analysis of damage}

The church of San Martino's dei Gualdesi, referring to the A-DC form [3, 4], has an intermediate damage index $\left(i_{d}=0.60\right)$. Although the $i_{d}$ value is slightly higher than the average of the Castelsantangelo's cluster (see $\S 2$ ), the church showed only a small collapse of the wall above the entrance (Figure 4d) but, any other structural element of the nave and the tower had not collapsed. The main damages are located in the internal part of the church, in particular near the pointed arches, in some parts of the perimeter wall and in the bell tower.

The cracks affecting the internal part of the church are mainly located between the longitudinal walls and the central arches. From the structure of the church, it is clear that the pointed arches, placed transversely to the nave, support the roof and transmit the loads to the side pillars and to the perimeter walls. Figure $4 \mathrm{~b}$ highlights some cracks between pillars and the longitudinal wall probably due to the weak connection in shear between the two. Moreover, it seems that some interactions in traction are present since some sliding in first voussoirs is present, probably due to the introduction of rebars and a consequent movement of the pillar according to the outof-plane of the lateral wall. 
More cracks are located at the interface between the extrados of the arch and the masonry, due to the absence of connection between the two different materials. In the same pictures (Figure $4 \mathrm{~b}$ ), reduced cracks are observed even at the level of the roof, perhaps due to the insertion of the metallic ring beam that may have limited their opening but also promoted the detachment.

Other cracks were located in the transverse walls of the nave, in particular in the north-west facade, which still has the shape of the original door. The distribution of the cracks follows the intersection between the original wall and the added element showing the typical shear cross shape (Figure 4a).

Lastly, deep cracks were found on the bell tower (Figure 4c). The position of these cracks is related to the presence of windows and small openings. The windows and the little columns of the upper level represent the weakest. However, although characterized by widespread cracks, the bell tower did not show the collapse of masonry parts or other elements. This prove the effectiveness of the past hooping interventions, which have defined a better connection between the orthogonal walls ensuring the box behavior during the seismic events.

Unlike the other facades of the church, the longitudinal wall located to the south shows a loss of the curtain wall with the detachment of the upper portion of the masonry (Figure 4d). The collapse of this masonry portion seems to be promoted by the reinforcement (of the past interventions) at the top. Indeed, if the metallic beam presents excessive stiffness, it can generate damages related to the tangential stresses in the contact area with the masonry and therefore a detachment between the parts. Moreover, the entire wall suffered from an out-of-plane displacement in the order of $15-20 \mathrm{~cm}$. The overall displacement of that seems to be provided by the monolithic behavior probably promoted and enhanced by injections.

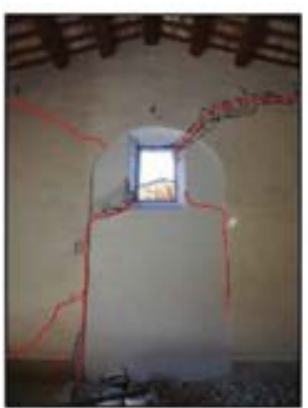

a)

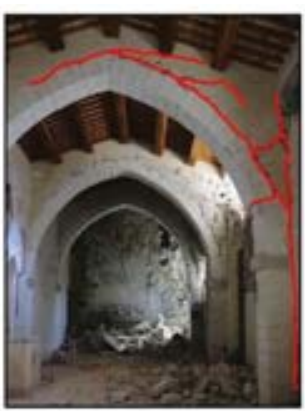

b)

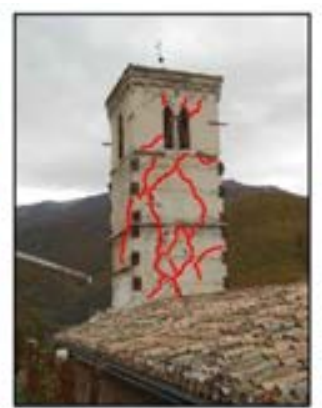

c)

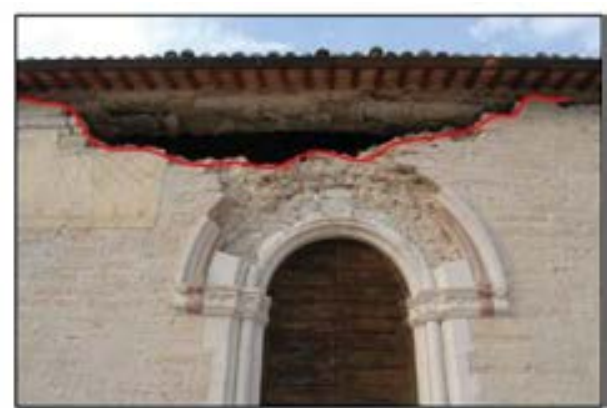

d)

Figure 4: Damages observed on the north-west facade (a), central arch (b), bell tower (c) and o the south-west facade.

\section{STRUCTURAL ANALYSIS}

The preliminary structural analysis of the church has focused on the pointed arch behavior and on the influence that this has on the overall behavior. With this aim, a kinematic study was performed together with a non-linear static analysis with a Finite Element Model in order to validate the assumptions made.

\subsection{Definition of the seismic action}

The seismic action used for the assessment of the church is determined by following the indications provided by the Italian Standard [12]. The design parameters used in the analysis are represented in Table 2. The return period, considering the ecclesiastical function, is of 712 years. 


\begin{tabular}{cccc|cccc}
\hline \multicolumn{3}{c}{ Parameters (DLS) } & \multicolumn{4}{c}{ Parameters (ULS) } \\
\hline $\boldsymbol{a}_{\boldsymbol{g}}$ & 0.120 & $\boldsymbol{q}$ & 1.00 & $\boldsymbol{a}_{\boldsymbol{g}}$ & 0.283 & $\boldsymbol{q}$ & 2.000 \\
\hline $\boldsymbol{F}_{\mathbf{0}}$ & 2.305 & $\boldsymbol{S}$ & 1.80 & $\boldsymbol{F}_{\mathbf{0}}$ & 2.400 & $\boldsymbol{S}$ & 1.554 \\
\hline $\boldsymbol{T}_{\boldsymbol{C}}{ }^{*}$ & 0.288 & $\boldsymbol{\eta}$ & 1.00 & $\boldsymbol{T}_{\boldsymbol{C}}{ }^{*}$ & 0.339 & $\boldsymbol{\eta}$ & 1.000 \\
\hline $\boldsymbol{S}_{\boldsymbol{S}}$ & 1.500 & $\boldsymbol{T}_{\boldsymbol{B}}$ & 0.15 & $\boldsymbol{S}_{\boldsymbol{S}}$ & 1.295 & $\boldsymbol{T}_{\boldsymbol{B}}$ & 0.170 \\
\hline $\boldsymbol{C}_{\boldsymbol{C}}$ & 1.584 & $\boldsymbol{T}_{\boldsymbol{C}}$ & 0.45 & $\boldsymbol{C}_{\boldsymbol{C}}$ & 1.500 & $\boldsymbol{T}_{\boldsymbol{C}}$ & 0.510 \\
\hline $\boldsymbol{S}_{\boldsymbol{T}}$ & 1.200 & $\boldsymbol{T}_{\boldsymbol{D}}$ & 2.08 & $\boldsymbol{S}_{\boldsymbol{T}}$ & 1.200 & $\boldsymbol{T}_{\boldsymbol{D}}$ & 2.726 \\
\hline
\end{tabular}

Table 2: Design parameters used in the analysis

\subsection{Kinematic analysis}

The kinematic analysis is based on the limit analysis and the principle of virtual works and refers to the upper bound solution [13]. This, on one hand, make easier the analysis and, on the other, it requires defining the minimum multiplier to obtain the exact solution. Therefore, the Finite Element Model helps in defining the proper crack pattern and hinges location.

The out-of-plane limit analysis was guided by the actual crack pattern observed, and hence evaluating those mechanisms activated during the earthquake (Figure 5). In detail, the southwest wall of the nave and the north-west corner of the tower were analyzed as out-of-plane mechanisms, while the central arch as in-plane mechanisms.
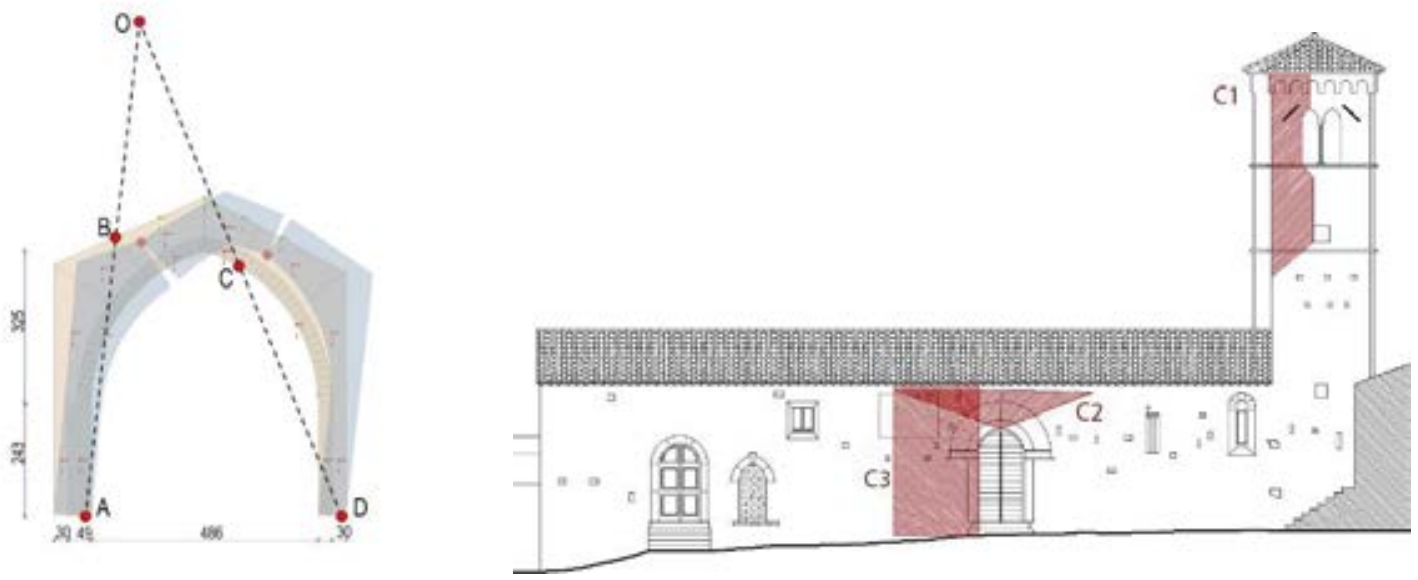

Figure 5: In-plane (left) and out-of-plane (right) analysis of the church.

Table 3 shows the results of the kinematic analysis implementing linear methods. The factor $\zeta$ is the safety coefficient defined as the ratio between the seismic capacity and the demand for each macro-element. Values greater than one indicate that the mechanism is verified at the damage limit state (DLS) and at the ultimate limit state (ULS). As regards the out-of-plane kinematic mechanisms, the linear verification is not verified for any mechanisms. The activation multiplier was calculated accounting for the masonry compression hence considering the hinge in the middle of the stress-block. The lower multiplier refers to the wall overturning (C3 Figure 5) and it figures out that the restrain contribution of the roof is not negligible, since that mechanism does not reach the collapse although it has activated with an overall ultimate displacement of about $15-20 \mathrm{~cm}$. The tower mechanism activated also on the real case but it was counteracted by the hooping system that avoided the collapse, as did not happen for the near church of S. Stefano. Lastly, the highest multiplier found (mechanism C2) of 0.535 has activated but not avoided by any interventions resulting in the collapse of the macro-element. That value is similar to the highest PGA recorded in the swarm of 0.541 the $26^{\text {th }}$ of October 2016. 


\begin{tabular}{|c|c|c|c|}
\hline \multicolumn{4}{|c|}{$1^{\circ}$ Mode } \\
\hline Kinematics & $\alpha(\mathrm{t} / 2)$ & $\zeta(\mathrm{DLS})$ & $\zeta(\mathrm{ULS})$ \\
\hline $\mathrm{C} 1$ & 0.266 & 0.38 & 0.44 \\
\hline $\mathrm{C} 2$ & 0.535 & 0.68 & 0.74 \\
\hline $\mathrm{C} 3$ & 0.143 & 0.58 & 0.57 \\
\hline
\end{tabular}

Table 3: Results of the kinematic analysis for the out-of-plane mechanisms

Similar to what has been observed for the out-of-plane mechanism, the hypothesis of interaction among macro-elements may lead to significantly different solutions also for in-plane analysis. Due to this, different combinations (Table 4) have been defined.

For the in-plane analysis of the arch, which is placed in the transversal direction of the nave ( $Y$ direction), the hinges position was defined by the analysis of the principal traction strains. The latter were obtained by the non-linear static analysis of the church, considering that this comes from static considerations which belong to the lower bound solution. Therefore, the obtained multiplier should be the exact one also for the interaction among longitudinal walls and the arch.

\begin{tabular}{|c|c|c|c|}
\hline & D1- All hinges as FEM & D2 - Hinge D on the impost \\
Case A \\
Only arch \\
$\begin{array}{c}\text { Case B } \\
\text { Only tension } \\
\text { between the arch and } \\
\text { the wall }\end{array}$ \\
$\begin{array}{c}\text { Sase C } \\
\text { Shear and tension } \\
\text { between the arch and } \\
\text { the wall }\end{array}$
\end{tabular}

Table 4: Type of kinematic analysis implemented

The possible variability may concerns the in-plane and out-of-plane interaction of the longitudinal wall and of the soil on the mountain side. Therefore, looking at Table 4, cases A, B, C considers different interactions among macro-elements whereas cases from D1 to D3 evaluate differently positions of the hinge on the mountain side (hinge D).

Table 5 reports the obtained activation multipliers $\alpha$, always considering the hinge regression, and the factor $\zeta$ that report the structural verification. Due to the not symmetric geometry, the multiplier of both directions is reported.

In case $\mathrm{A}$ the arch is alone, neglecting the contributions of lateral walls, whereas in cases $\mathrm{B}$ and $\mathrm{C}$ walls are considered. In the latter the coupling between the arch and the wall is perfect, 
with transmission of normal and shear stresses on the interface, while in case B only the normal action is considered.

\begin{tabular}{|c|c|c|c|c|c|c|c|c|c|}
\hline \multicolumn{5}{|c|}{$2^{\circ}$ Mode $(+Y)$ North/mountain dir. } & \multicolumn{5}{|c|}{$2^{\circ}$ Mode $(-Y)$ South/valley dir. } \\
\hline & case & $\alpha(\mathrm{t} / 2)$ & $\zeta(\mathrm{DLS})$ & $\zeta(\mathrm{ULS})$ & & case & $\alpha(\mathrm{t} / 2)$ & $\zeta(\mathrm{DLS})$ & $\zeta(\mathrm{ULS})$ \\
\hline \multirow{3}{*}{ D1 } & A & -0.002 & - & - & \multirow{3}{*}{ D1 } & A & 0.079 & 0.34 & 0.34 \\
\hline & B & 0.188 & 0.80 & 0.79 & & B & 0.172 & 0.73 & 0.72 \\
\hline & $\mathrm{C}$ & 0.189 & 0.80 & 0.79 & & $\mathrm{C}$ & 0.184 & 0.78 & 0.77 \\
\hline \multirow{3}{*}{ D2 } & A & -1.030 & - & - & \multirow{3}{*}{ D2 } & A & 0.108 & 0.45 & 0.44 \\
\hline & $\mathrm{B}$ & 0.065 & 0.28 & 0.28 & & $\mathrm{~B}$ & 0.137 & 0.59 & 0.59 \\
\hline & $\mathrm{C}$ & 0.064 & 0.28 & 0.27 & & $\mathrm{C}$ & 0.159 & 0.69 & 0.68 \\
\hline \multirow{3}{*}{ D3 } & A & -0.550 & - & - & \multirow{3}{*}{ D3 } & A & 0.107 & 0.44 & 0.44 \\
\hline & B & 0.277 & 1.16 & 1.14 & & B & 0.161 & 0.68 & 0.67 \\
\hline & $\mathrm{C}$ & 0.306 & 1.28 & 1.26 & & $\mathrm{C}$ & 0.198 & 0.83 & 0.82 \\
\hline
\end{tabular}

Table 5: Results of the kinematics analysis for the in-plane mechanisms

In the case $A$, in the positive direction of $Y$, there is a negative multiplier that means that there is no equilibrium in the thrust of the arch without the lateral walls providing a counterbalancing effect even in static conditions. Therefore, the case $\mathrm{A}$ is not a reliable hypotheses of the actual behavior. Considering the fact that the FEM model reliably describes the hinge positions, and comparing with the actual observations, also cases D2 and D3 are not suitably describing the real situation because did not appear evident cracks next to the guessed hinge position D.

In conclusion, the cases more similar to the actual situation are $\mathrm{B}$ and $\mathrm{C}$ in conditions $\mathrm{D} 1$. Herein, case B is selected as the most reliable (Table 5 in bold) because even the intervention with rebars performed in 2014 could not guarantee the shear transfer, as pointed out by the crack pattern occurred (Figure 4b). Therefore the final multipliers selected are $\alpha 0.188$ and 0.172 in the positive and negative $\mathrm{Y}$ direction respectively.

\subsection{Fem analysis}

The numerical analysis of San Martino's dei Gualdesi was performed using the DianaFea software. In detail, a linear and a non-linear static analysis were performed in order to obtain results consistent with the actual damages observed.

The church has modeled using two-dimensional elements. The roof analysis of weight has performed following the information obtained by documents on past interventions. The vertical elements of the model have defined as regular curved shells: quadrilateral elements with eight nodes and a quadratic behavior. The mesh has a size of $0.25 \mathrm{~m}$. The linear elements such as beams have specified as beam elements curved and characterized by three nodes (Class-III 3D). Boundary conditions were defined to constrain all translations and two rotations except the outof-plane. Finally, the material properties were defined following Table 1 for the linear properties. To account for the non linear behavior a total strain cracked model has been adopted with a parabolic behavior in compression and a exponential one for the softening in tension. The fracture energy has defined following the literature [14].

First, a linear static analysis was performed to evaluate the static conditions of the model. Regarding the reaction forces, the maximum vertical value is $74.9 \mathrm{kN}$. The vertical deformation ( $\mathrm{Z}$ direction), due to its own weight, is located on the bell tower and is approximately $1.7 \mathrm{~mm}$. Lastly, as regards the main stresses, the compression stress located at the base of the bell tower is $0.45 \mathrm{MPa}$. 
Subsequently, the static non-linear analysis was implemented to analyze the non-linear behavior of the structure. The analysis concerns both the longitudinal (X) and transverse directions of the church (Y), with more attention to the transversal direction (east-west direction). The own weight of the structure was applied in a single load step, followed by the application of a global acceleration (proportional to the masses) into different load steps.

Results show greater deformations and displacements refer to the analysis with transverse direction of the seismic action $(+Y,-Y)$. In the first case (+Y, mountain dir.), the displacements of the control nodes positioned at the top of the central arch are approximately equal to $0.20 \mathrm{~m}$ in agreement with the actual observations. Analyzing the results relating to strains, the main stresses are located on the transversal walls. However, high cracks are also located on the longitudinal facades of the church and on the tower's walls (Figure 6).

In the negative direction of $Y(-Y$, valley dir.), the greatest displacement is measured at the top of the bell tower $(0.12 \mathrm{~m})$ even the control nodes at the top of the central arch reach considerable displacements of $0.10 \mathrm{~m}$.

Regarding the analysis in the longitudinal direction $(+X,-X)$ the main deformations and displacements are located on the upper part of the bell tower.
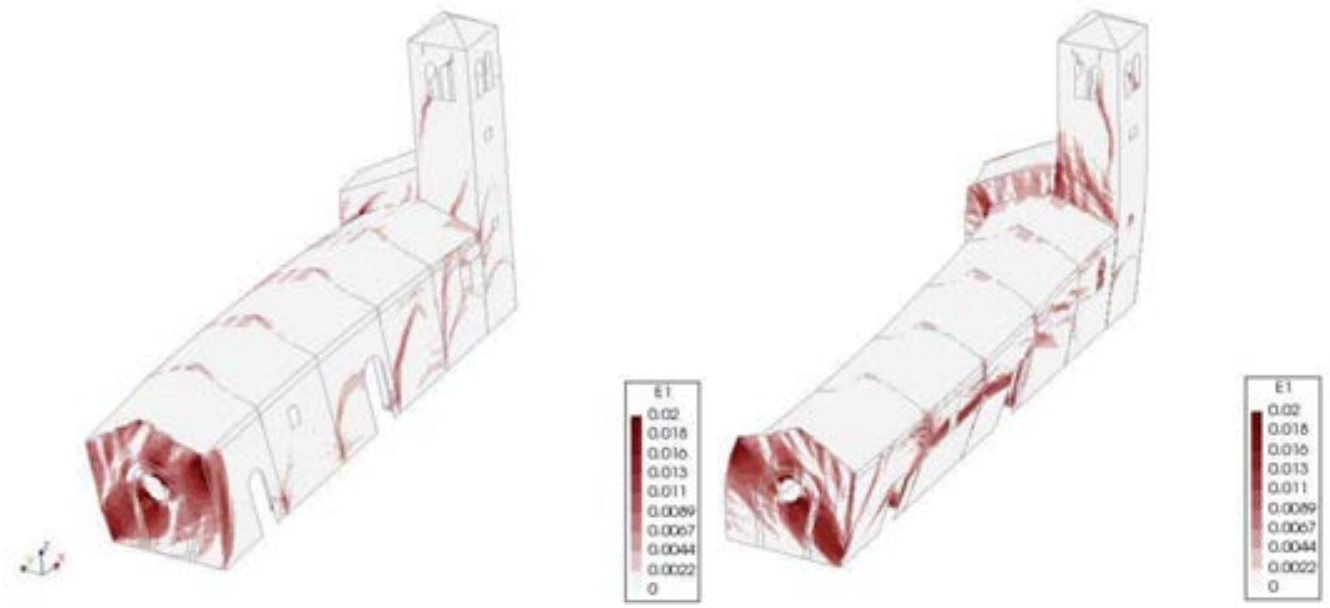

Figure 6: Major principal strain for the analysis in the $+Y$ direction (left) and $-Y$ direction (right).

\subsection{Comparison between the damages observed and the numerical analysis}

The results obtained from the numerical analysis has been compared with the damages described in the previous paragraph (§3.2). The structural parts investigated are the north-west and the south-west facade of the nave, the walls of the bell tower and finally the internal arches of the nave.

Figure 7a shows that strains, and thus cracks concerning the internal arch, are mainly located between its lateral part and the longitudinal part of the south-western masonry and in the interface between the extrados of the arch and the masonry above. From this crack pattern, the four hinges location for the limit analysis presented above was defined (\$4.2).Moreover, damages and cracks coincide with the damages observed in the on-site survey (Figure 4b), confirming the reliability of this type of analysis.

Less deformation and damages occurred in the north-east walls, again corresponding to the actual condition. In this case, the pillars are embedded in the wall itself, ensuring a better connection between them. The greatest displacements are reached in the analysis with transverse direction of the seismic action. 
The longitudinal south-west wall showed significant damage due to the longitudinal action. Figure $7 \mathrm{~b}$ shows cracks on the entire wall and in particular near the transverse arches and openings. More cracks are located in the interface between the wall of the bell tower and in the upper part of the nave facade. These damages coincide also with the current state of the church.

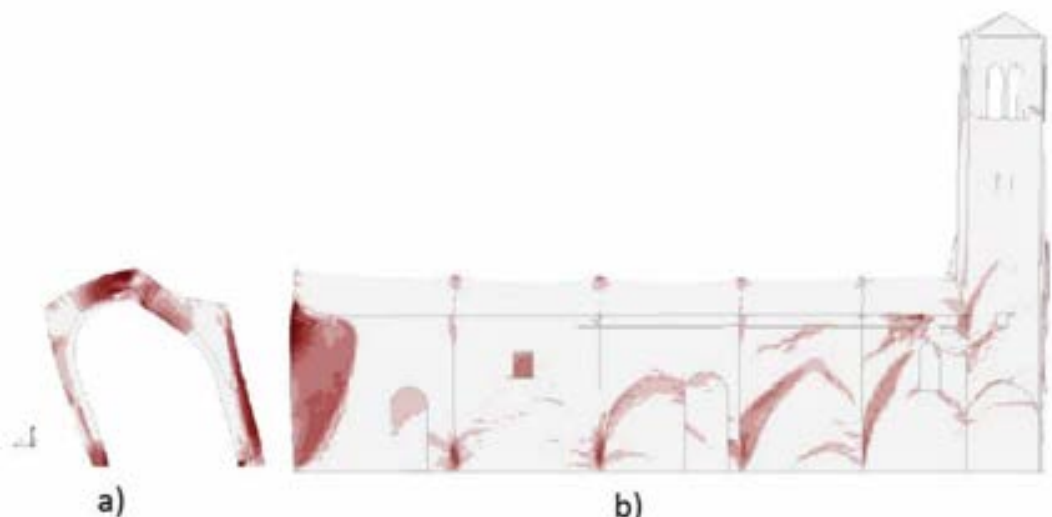

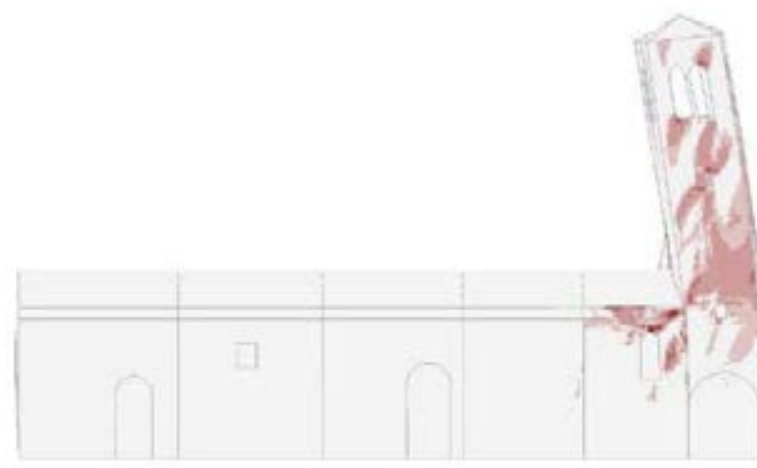

c)

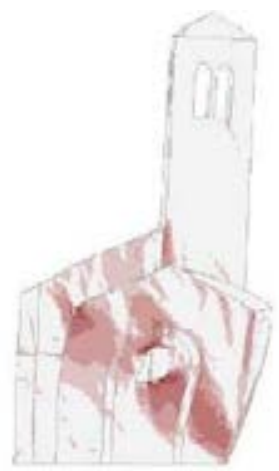

d)

Figure 7: Localized deformations in the central arch (a), south-west wall (b), tower (c) and north-west wall (d).

The north-west facade is characterized by significant damages in the case of transverse seismic action. Cracks obtained from the numerical model provide almost the same pattern observed in the structure. The distribution of cracks follows the intersection between the original wall and the added element.

Lastly, the south-western wall of the bell tower shows significant deformations due to the longitudinal action (-X). The principal strains, obtained from the numerical model, are located near the mullioned windows, in the small openings below and lastly in the contact area between the roof of the church and the belfry. These critical points are also observed on the damage picture (Figure 4c).

\section{CONCLUSIONS}

- The paper presents the first stage of studies carried out on the San Martino's dei Gualdesi church, confirming that the integrated methodology among different type of analysis (i.e. kinematic and non-linear static analysis) lead to achieve reliable results compared to the real case observations.

- The kinematic analysis, supported by some non-linear analysis in the definition of the mechanisms, proved to be a valuable tool in the definition of the activating accelerations. 
The evaluation of the interaction in-plane and out-of-plane may also be detrimental to obtain the correct value.

- The static non-linear analysis confirms to be a reliable method of structural modeling detecting a crack pattern very similar to the real one.

- Future works aim at evaluating through capacity curves the real performances of the structure, even compared with the real occurred earthquake, and furtherly improving analysis by the implementation of interventions.

\section{ACKNOWLEDGMENTS}

The authors wants to acknowledge Sara Coppo and Estefania Chaves Moreno to their preliminary contributions on the research. Special thanks are due to the Italian Department of Civil Protection (DPC), which funded this study in the framework of the ReLUIS-DPC Project 20192021 - Work Package 5: Interventi su edifici vincolati monumentali elo di culto.

\section{REFERENCES}

[1] E. Cescatti, P. Salzano, C. Casapulla, D. Ceroni, F. da Porto, A. Prota, Damages to masonry churches after 2016-2017 Central Italy seismic sequence and definition of fragility curves. Bull Earthquake Eng, 18, 297-329, 2020.

[2] A. Penna, C. Calderini, L. Sorrentino, C.F. Carocci, E. Cescatti, R. Sisti, A. Borri, C. Modena, A. Prota, Damage to churches in the 2016 central Italy earthquakes. Bull Earthquake Eng, 17, 5763-5790, 2019.

[3] DPCM 23/02/2006, Approval of forms for the seismic damage assessment of cultural heritage buildings. G.U. no. 55, 7/03/2006, 2006. (in Italian)

[4] MiBACT, Direttiva 23 aprile 2015, Aggiornamento della direttiva 12 dicembre 2013, relativa alle "Procedure per la gestione delle attività di messa in sicurezza e salvaguardia del patrimonio culturale in caso di emergenze derivanti da calamità naturali. GU Serie Generale n.169 del 23-7-2015, 2015. (in Italian)

[5] Italian Ministry of Public Building and Works, G.U. no. 47. 2011, February 26. (suppl. ord. no. 54). Directive of the Prime Minister dated on 9/02/2011, Assessment and mitigation of seismic risk of cultural heritage with reference to the Technical Code for the design of constructions, issued by D.M. 14/1/2008, 2011. (in Italian)

[6] S. Lagomarsino, S. Podestà, Seismic Vulnerability of ancient churches: II. Statistical analysis of surveyed data and methods for risk analysis. Earthquake Spectra, 20(2), 395412, $2004 b$.

[7] E. Cescatti, M. Secco, F. da Porto, G. Artioli, C. Modena, L. Xu, Characterization of mortar and stone masonry quality in Amatrice historical buildings hit by the 2016 central Italy earthquake. $17^{\text {th }}$ International Brick and Block Masonry conference. Kraków, Poland, July 5-8, 2020. DOI:10.1201/9781003098508-65

[8] A. Borri, C. Corradi, G. Castori, A. De Maria, A method for the analysis and classification of historic masonry. Bulletin of Earthquake Engineering, 13(9), 2647-2665, 2015. 
[9] Italian Ministry of Infrastructures, Circolare Esplicativa 21 gennaio 2019, n. 7 C.S.LL.PP. Istruzioni per l'applicazione dell' "Aggiornamento delle 'Norme tecniche per le costruzioni"» di cui al decreto ministeriale 17 gennaio 2018, Rome, 2019. (In Italian)

[10] A. Vignoli, S. Boschi, C. Modena, E. Cescatti, In-situ mechanical characterization of existing masonry typologies: A research project in Italy finalized to update the structural codes. $16^{\text {th }}$ International Brick and Block Masonry conference, Padova, Italy, 26-30 June, 2016.

[11] Italian Ministry for Cultural Heritage and Activities, LL.GG.BB.CC. Linee guida per la valutazione e riduzione del rischio sismico del patrimonio culturale. Rome, 2010. (In Italian)

[12] D.M. 17/01/2018. Norme Tecniche per le Costruzioni (NTC 2018). Gazzetta Ufficiale, n. 42 del 20/02/2018, Supplemento ordinario n.8, Rome, 2018. (In Italian)

[13] M. Gilbert M, Limit analysis applied to masonry arch bridges: state-of-the-art and recent developments. 5th International Conference on Arch Bridges, Madeira, Portugal, 12-14 September, 2007.

[14] P.B. Lourenço, Recent advances in masonry modeling: micromodelling and homogenisation. In: U. A. M. H. Galvanetto, ed. Multiscale Modeling in Solid Mechanics: Computational Approaches. London, Imperial College Press, 2009. 